ISSN 1983-8484

Licenciado sob uma Licença Creative Commons

\title{
Redes estratégicas para a inovação: um estudo multicaso de incubadoras paranaenses
}

\author{
Strategic network for innovation: a multicase study of Paraná incubators
}

Maurício Reinert do Nascimento ${ }^{[a]}$, Jaiane Aparecida Pereira ${ }^{[b]}$, Alessandra Cenerino ${ }^{[c]}$, Márcia Cristina David de

Souza ${ }^{[\mathrm{d}]}$, Deborah Stocco Machado ${ }^{[\mathrm{e}]}$, Letícia Veríssimo da Silva ${ }^{[f]}$, Cristiani Passolongo Noveli[g]

[a] Doutor em Administração pela Fundação Getúlio Vargas (FGV), professor adjunto da Universidade Estadual de Maringá (UEM), Maringá, PR - Brasil, e-mail: mrnascimento@uem.br

[b] Mestre em Administração pela Universidade Estadual de Maringá (UEM), professora assistente da Faculdade de Jandaia do Sul (FAFIJAN), Jandaia do Sul, PR - Brasil, e-mail: profjaiane@yahoo.com.br

[c] Mestre em Administração pela Universidade Estadual de Maringá (UEM), professora da Faculdade Ciodonto e Unifamma, Maringá, PR - Brasil, e-mail: acenerino@gmail.com

[d] Mestre em Administração pela Universidade Estadual de Maringá (UEM), professora da Faculdade Dinâmica das Cataratas (UDC), Foz do Iguaçu, PR - Brasil, e-mail: mcris.david@gmail.com

[e] Graduação em Administração pela Universidade Estadual de Maringá (UEM), Maringá, PR - Brasil, e-mail: deborah.machado@ gmail.com

[f] Graduação em Administração pela Universidade Estadual de Maringá (UEM), Maringá, PR - Brasil, e-mail: leticia_56197@ hotmail.com

[g] Mestre em Administração pela Universidade Estadual de Maringá (UEM), professora colaboradora da Universidade Estadual de Maringá, PR - Brasil, e-mail: cpassalongo@gmail.com

\section{Resumo}

O objetivo deste artigo é analisar, em redes estratégicas, se a incubadora, a partir da perspectiva dos seus gestores, atua como intermediária das empresas incubadas no acesso a informação para o desenvolvimento de inovação. Para alcançá-lo, discute-se no quadro teórico sobre inovação, informação e redes estratégicas, que são observadas a partir dos relacionamentos da incubadora. Foi realizado um estudo multicaso descritivo-qualitativo em três incubadoras localizadas no interior do estado do Paraná: (1) Incubadora Tecnológica de Maringá, (2) Incubadora do Parque Tecnológico Itaipu (PTI) e (3) Centro Incubador Tecnológico de Cascavel (CIT/FUNDETEC). Foram coletados dados por meio de entrevistas com os gestores dessas organizações. Os dados foram analisados utilizando-se de análise de conteúdo com auxilio do software Atlas.ti. Entre os principais achados, destacam-se: (1) as incubadoras têm consciência da sua importância como mediadores, mas de maneira geral atuam mais como incentivadores informais na formação de relacionamentos; (2) existe uma diversidade nos tipos de empresas que são incubadas, o que propicia uma oportunidade de acesso a informação ao mesmo tempo em que dificulta o trabalho de cooperação dessas empresas, especialmente devido à dificuldade de comunicação; (3) a diferença na percepção do tempo entre a incubadora, incubadas e demais 
parceiros complica o trabalho em conjunto; e (4) as inovações possuem baixo grau de novidade, sendo mais incrementais.

Palavras-chave: Redes estratégicas. Inovação. Incubadora.

\section{Abstract}

The objective of this paper is to analyze in strategic networks, if the incubator, from the perspective of their managers, acts as intermediary of the incubated companies to information access for innovation development. To achieve this, we discuss theoretical framework on innovation, information and strategic networks, which are observed from the relationships of the incubator. We conducted a multicase study descriptive-qualitative with three incubators located in the state of Paraná: (1) Technological Incubator in Maringá, (2) Incubator of Itaipu Technological Park (ITP) and (3) Technology Incubation Center in Cascavel (CIT/FUNDETEC). We data collected through interviews with managers of these organizations. We data analyzed using content analysis with the aid of a software Atlas.ti. Among the main findings are: (1) incubators is aware of its importance as mediators but generally acts more as informal encourage in formation of relationships, (2) there is a diversity in businesses that are incubated, which provides an opportunity to information access while making it difficult to work in cooperation of these companies, especially the difficulty of communication, (3) the difference in time perception among the incubator, incubated, and other partners complicates group work, and (4) innovations have a low novelty degree, there are more incremental.

Keywords: Strategic networks. Innovation. Incubator.

\section{Introdução}

Não existe dúvida de que a inovação é diferencial para o desenvolvimento de países e empresas (MOWERY; ROSENBERG, 2005). As questões que ainda precisam ser respondidas são referentes a como é possível melhorar o desempenho na geração e difusão de inovação (ROGERS, 2003). Uma das respostas parece ser a criação e o fortalecimento das incubadoras, espaços destinados ao desenvolvimento de empreendimentos inovadores. A incubadora é responsável por dar suporte para gerenciamento interno desses empreendimentos e auxiliá-los na relação com o ambiente externo (ANPROTEC, 2011).

Dentro da incubadora formam-se redes estratégicas que podem orientar o futuro das empresas. As redes são vistas como um aglutinador social que envolve indivíduos e organizações unidos em um sistema coerente, o que caracteriza as redes de interdependências encontradas nos distritos industriais e representa práticas como: contratos relacionais, produção colaborativa ou alianças interorganizacionais (POWELL; SMITH-DOERR, 1994).

Parte-se então da premissa de que a incubadora, juntamente com as empresas incubadas, formam uma rede estratégica que dá suporte a relacionamentos e troca de informações importantes ao desenvolvimento da inovação. Desta maneira, surge a seguinte questão: de que maneira, em uma rede estratégica, a incubadora atua como intermediária das empresas incubadas no acesso a informação para o desenvolvimento de inovação?

Para responder a essa indagação, o objetivo da pesquisa é analisar, em redes estratégicas, se a incubadora, a partir da perspectiva dos seus gestores, atua como intermediária das empresas incubadas no acesso a informação para o desenvolvimento de inovação. De forma específica, o trabalho procura: (1) descrever o funcionamento e o processo de atuação das incubadoras; (2) identificar se a rede estratégica formada pela incubadora e pelas incubadas auxilia no acesso a informação e na inovação; e (3) discutir sobre a atuação e o suporte ofertado pelas incubadoras.

A pesquisa visa contribuir para a área de redes estratégicas e inovação trazendo um olhar da inovação por meio dos relacionamentos e da troca de informações, dando atenção não apenas aos aspectos técnicos ligados as incubadoras, mas focando nos relacionamentos que as envolvem e como esses relacionamentos podem contribuir para o desenvolvimento de inovação nas incubadas. 
Inicialmente o artigo apresenta uma discussão sobre inovação, informação e redes estratégicas, depois sobre o papel da incubadora. Posteriormente foi exposta a metodologia da pesquisa e, em seguida, a apresentação dos casos com as considerações finais.

\section{Referencial teórico}

Para o desenvolvimento dos objetivos propostos, o referencial abordado está estruturado em duas partes. Primeiramente, discutem-se estudos sobre inovação, informação e redes estratégicas. Em um segundo momento, foram enfatizadas as incubadoras, visando esclarecer conceitos-chave para a pesquisa proposta.

Inovação, informação e redes estratégicas

A inovação tem sido, nos dias de hoje, presença obrigatória nas estratégias de desenvolvimento ao redor do mundo. Ela é uma das "mais significativas fontes de desempenho econômico das nações" (ARBIX, 2010, p. 70), pois tem levado ao aumento de produtividade e a criação de empregos de melhor qualidade. Tem-se observado, na maioria dos países, o aumento do investimento em Pesquisa e Desenvolvimento (P\&D) para a geração de inovações (BESSANT; TIDD, 2009). Isso se deve ao fato de que a inovação traz vantagem competitiva, incentivando a competitividade entre as empresas, e de certo modo, intensificando a pressão para se colocar algo novo no mercado ou reinventar o que já era conhecido (ARBIX, 2010).

Para se entender a adoção e geração de inovação pelas organizações é importante compreender o que é inovação e as suas tipologias (MOREIRA; QUEIROZ, 2007). O conceito de inovação é bastante utilizado no sentindo de "algo novo", no entanto existem questionamentos sobre o que seria esse "novo". A palavra inovação pode ser empregada em três diferentes contextos: (1) como sinônimo de invenção; (2) como um processo de inovação, ou seja, a adoção de uma mudança que é nova para a organização; e (3) como uma ideia que foi inventada, independente de sua adoção ou não (MOREIRA; QUEIROZ, 2007).

Além disso, é preciso considerar os aspectos que influenciam a inovação, e a respeito deles pode-se fazer uma primeira divisão: (1) fatores internos; e (2) fatores externos. Os fatores internos se referem às características da própria organização; os fatores externos estão relacionados ao ambiente em que a organização está inserida (DAMANPOUR; SCHNEIDER, 2006).

Entre os fatores internos, destacam-se: liderança, gestão de pessoas, gestão da criatividade e gestão do conhecimento (PRAJOGO; AHMED, 2006). A inovação decorre do conhecimento, e esse conhecimento está relacionado às ideias e aos ideais, ou seja, "a essência da inovação é recriar o mundo segundo uma visão ou um ideal específico" (NONAKA, 1997, p. 29). Logo, as empresas para serem inovadoras devem ser criadoras de conhecimento, e por esse motivo, aprender técnicas para a criação de um ambiente organizacional voltado à inovação.

Sabendo que o conhecimento começa no indivíduo, é pessoal, é necessário que ele se torne organizacional. A organização deve propiciar um ambiente que possibilite a troca de informações. No entanto, o que dificulta essa transferência é que, muitas vezes, os conhecimentos são tácitos, difíceis de transferir de um indivíduo para o outro, então a solução seria torná-lo explícito (NONAKA, 1997).

A partir da troca de informações entre os indivíduos na organização, entre organizações e com o ambiente, surge fomento para a geração de inovação. Segundo Albagli e Maciel (2004, p. 11), "o grau de inovação aumenta com a variedade de parceiros comunicando-se em redes". A diversidade de informações que procedem de diferentes fontes é mais propícia à inovação do que a concentração em apenas um tipo de interação (ALBAGLI; MACIEL, 2004), ou seja, os atores geram conhecimento compartilhando informação (TOMAÉL et al., 2005), porém é importante ressaltar que a informação é apenas uma parte do processo do conhecimento (TÁLAMO, 2004), sendo que existe facilidade para a transferência de informações, já conhecimento em si é mais difícil de transferir, pois possui elementos que estão enraizados em pessoas, organizações ou locais específicos (LEMOS, 1999).

Com relação aos fatores externos, destaca-se a incerteza ambiental (ARBIX, 2010). A inovação normalmente tem sido gerada em ambientes de incerteza, pois ele é mais propício a novas ideias. A inovação não obedece a um padrão linear, contínuo e regular, características dos ambientes estáveis, pois a solução dos problemas existentes e as consequências das resoluções a princípio são desconhecidas (LEMOS, 1999). Além da incerteza, o contexto ambiental oferece oportunidades para a organização, entre as quais, 
tecnologia, recursos e informação (DAMANPOUR; SCHNEIDER, 2006).

0 acesso a oportunidades no contexto ambiental ocorre por meio de relacionamentos (GRANOVETTER, 1985; UZZI, 1997). Entre os modelos que se propõem a explicar a inovação por meio dos relacionamentos, está o da hélice tripla, em que a inovação é explicada por meio do relacionamento entre três segmentos: empresas, universidades e Estado (MACIEL, 2001). Todavia, essa teoria, entre outras, formula modelos de inovação por meio do cruzamento de informações, tudo em função da demanda e da oferta, sendo que ao final não explicam como os processos de inovação aparecem e se desenvolvem (ANDRADE, 2005). A partir dos anos 1990 estabeleceu-se um novo conceito, o sistema nacional de inovação, em que:

interações entre os agentes econômicos, as instituições de pesquisa e os organismos governamentais estipulam ações recíprocas que geram a capacidade de desenvolvimento de condições de inovação [...]. A construção de novos formatos organizacionais e a ênfase em atividades de parceria, prestação de serviços, intercâmbios e convênios envolvendo empresas, governos, universidades, incubadoras e centro de pesquisas em regra múltiplas e variáveis passaram a constituir a precondição para qualquer inovação (ANDRADE, 2005, p. 148).

Dentro desse contexto, destaca-se o papel das redes estratégicas para desenvolvimento de inovações. As empresas não devem ser analisadas como entidades autônomas, mas sim ligadas umas às outras em redes de recursos e fluxos, ou seja, através de redes estratégicas (GULATI; NOHRIA; ZAHEER, 2000). Essas redes englobam um conjunto de relações, tanto horizontal quanto vertical, com outras organizações, sejam elas fornecedores, clientes, concorrentes ou outras entidades. Elas são compostas por laços interorganizacionais duradouros e de importância estratégica para a empresa.

As redes estratégicas podem ser vistas como:

estruturas de relações comerciais colaborativas entre empresas, as quais formam alianças para atingir objetivos de interesse comum, sob a coordenação e a liderança de uma empresa focal, com base em regras pré-acordadas, confiança e interdependência, compartilhando recursos e conhecimento para ampliar seu capital intelectual, desenvolvendo com- petências e ganhando competitividade individualmente, ao mesmo tempo em que um capital social próprio da rede é construído (DIAS, 2009, p. 27)

Parte do sucesso da empresa está relacionada ao uso exclusivo dos seus recursos, mas parte está relacionada à estrutura da rede que a empresa pertence. As empresas cujos relacionamentos permitem ocupar um lugar mais central nas redes estratégicas tendem a alcançar maiores retornos, pois têm acesso a informações de melhor qualidade e oportunidades diferenciadas, em contrapartida àquelas empresas que estão em uma localização periférica na rede (GULATI; NOHRIA; ZAHEER, 2000).

Além da posição na estrutura da rede, o tipo de relação dentro dela também define o acesso a oportunidades (UZZI, 1997). Nas redes existem relações sociais ou laços de um tipo específico. Um laço ou relação entre dois atores tem força e conteúdo. A força do laço é uma combinação da quantidade de tempo, intensidade emocional, intimidade e serviços recíprocos que o caracterizam, podendo ser fraco, forte ou ausente (GRANOVETTER, 1973). 0 conteúdo pode incluir informação, conselho ou amizade, interesses comuns ou associação, e tipicamente algum nível de confiança (CASTILLA et al., 2000).

Diante do importante papel das redes estratégicas, surgem espaços como as incubadoras, que visam criar uma estrutura interna propícia à gestão da empresa, fornecendo acesso a recursos, tecnologia e troca de informação. 0 próximo tópico apresenta discussões sobre incubadoras.

\section{Incubadoras}

A criação de incubadoras no Brasil vem se intensificando, principalmente na última década, devido a diversos incentivos governamentais e de institutos de pesquisa. Dentre os programas atualmente orientados para o desenvolvimento do empreendedorismo no Brasil, está a intensificação da criação de incubadoras tecnológicas, incentivando a aproximação e integração com universidades e centros de pesquisa (MACHADO; GREATTI; JESUS, 2010).

A ideia de empresas incubadoras vem dos Estados Unidos, da região do Vale do Silício, na Califórnia (LAHORGUE, 2004). Elas foram criadas nos anos 70 para incentivar recém-graduados a crescerem na vida empreendedora. Nos anos 80 é que apareceram as 
primeiras incubadoras no Brasil (ANPROTEC, 2011). De acordo com a ANPROTEC (Associação Nacional de Entidades Promotoras de Empreendimentos Inovadores), o Brasil possui cerca de 400 incubadoras com 6300 empresas, sendo 2800 incubadas, 2000 associadas e 1500 graduadas (ANPROTEC, 2011).

As incubadoras surgiram com o intuito de ajudar pequenos empreendimentos a se desenvolverem (BEUREN; RAUPP, 2010). A implantação e o fortalecimento das incubadoras buscam: (1) promover o desenvolvimento econômico; (2) promover a comercialização de tecnologias; (3) promover o desenvolvimento de propriedades imobiliárias; e (4) promover o empreendedorismo (VEDOVELLO; FIGUEIREDO, 2005). As incubadoras chamam a atenção por oferecer treinamento, orientação, apoio, incentivo e, acima de tudo, infraestrutura e assessoria para as organizações incubadas (CASTRO; MACHADO, 2007).

Existem vários tipos de incubadoras, e Zedtwitz desenvolveu uma tipologia que foi adaptada por Vedovello e Figueiredo (2005), sendo as incubadoras classificadas como: (1) incubadoras comerciais independentes, que são resultados de atividades desenvolvidas por empresários ou empresas ligadas ao capital de risco; (2) incubadoras regionais, que normalmente são implantadas por governos locais ou organizações com interesses locais; (3) incubadoras vinculadas às universidades, nas quais as universidades servem de base para essas incubadoras; (4) incubadoras intraempresariais, que estão ligadas a alguma organização no seu setor de P\&D; e (5) incubadoras virtuais, que não possuem espaço físico, mas oferecem redes de acesso a empresários (VEDOVELLO; FIGUEIREDO, 2005).

Antes de serem empresas incubadas, os projetos podem passar por um período de pré-incubação, que é um conjunto de atividades que visa estimular o empreendedor e preparar projetos que tenham potencial de negócios em um curto período de tempo, de seis meses a um ano. Nesta fase é dada grande ênfase ao plano de negócios, à pesquisa de mercado e à preparação dos empresários sobre gestão de negócios. Essa fase também pode ser chamada de hotel de projetos, hotel de ideias, hotel tecnológico, etc. (ANPROTEC/SEBRAE, 2002).

Após o período de incubação, a empresa recebe o nome de graduada ou liberada, que é aquela organização que passou pelo processo de incubação e alcançou desenvolvimento suficiente para ser habilitada a sair da incubadora, todavia, essa empresa pode continuar mantendo vínculo com a incubadora na condição de associada (ANPROTEC/SEBRAE, 2002).

A incubadora que abriga empresas de base tecnológica é uma estrutura que prioriza o desenvolvimento de empresas onde a tecnologia dos produtos, processos ou serviços representam alto valor agregado (MINISTÉRIO..., 2009). Sendo assim, as incubadoras surgem como fomentadoras do processo de inovação, podendo ser um instrumento de propagação de informações através de suas redes sociais.

\section{Procedimentos metodológicos}

A presente pesquisa caracteriza-se como qualitativo-descritiva (DENZIN; LINCONL, 1994; TRIVIÑOS, 2008). Utilizou-se o estudo multicaso como desenho de pesquisa (YIN, 2003; GODOY, 2006), com corte de investigação transversal (RICHARDSON, 2008). Foram pesquisadas três incubadoras, localizadas no estado do Paraná: (1) Incubadora Tecnológica de Maringá, (2) Incubadora do Parque Tecnológico Itaipu (PTI) e (3) Centro Incubador Tecnológico de Cascavel (CIT/ FUNDETEC). Foram coletados dados primários, construídos por meio de entrevistas semiestruturadas (FONTANA; FREY, 1994) com os gestores das incubadoras selecionadas e dados secundários por meio do site das incubadoras juntamente com documentos internos, tais como editais, regimento, entre outros.

As entrevistas foram realizadas entre outubro de 2009 e março de 2011. Na Incubadora Tecnológica de Maringá foram entrevistados um membro do conselho gestor (E1), o diretor de projetos (E2) e a gerente administrativa (E3). Na incubadora do PTI foram entrevistados o gerente (E4) e o analista de negócios (E5). No CIT/FUNDETEC foi entrevistado um membro da gerência da incubadora (E6). A duração média das entrevistas foi de 50 minutos.

A condução das entrevistas foi efetuada da seguinte forma: primeiro buscou-se investigar particularidades do processo de seleção; depois descobrir sobre o apoio ofertado durante o período de incubação e se existia um acompanhamento das incubadas; em seguida, analisou-se a atuação da incubadora com relação a treinamento e suporte gerencial, acesso ao mercado e a informações; e por fim, investigou-se sobre a formação dos relacionamentos e a inovação.

As entrevistas foram gravadas, posteriormente transcritas e depois apresentadas aos seus respectivos participantes para observação de consonância do 
que foi informado com o descrito (CRESWELL, 2007), utilizando-se de protocolos (CONE; FOSTER, 2006). Para análise das entrevistas, optou-se pela análise de conteúdo (BARDIN, 1977; BAUER, 2007). Para auxiliar na realização da análise dos dados foi utilizado o software Atlas.ti (BANDEIRA-DE-MELLO, 2006).

\section{Apresentação dos casos e análise dos resultados}

As incubadoras paranaenses selecionadas para o estudo são associadas a REPARTE - Rede Paranaense de Tecnologia e Inovação (REDE..., 2011) e também fazem parte da ANPROTEC (ANPROTEC, 2011). Primeiramente foram descritas as particularidades de cada incubadora de forma sucinta. Em seguida foi apresentada uma análise das três incubadoras, identificando o processo de seleção, o apoio ofertado às incubadas e o acompanhamento do desempenho das mesmas. Por fim, foi exposta uma discussão sobre a atuação das incubadoras em relação ao mercado e à informação, juntamente com suas redes de relacionamentos e a inovação.

\section{Descrição das incubadoras}

A Incubadora Tecnológica de Maringá surgiu em 1996 com o nome de Centro Softex Genesis de Maringá (CSG InfoMar), atendendo ao edital do CNPq do Programa Brasileiro de Software para Exportação (SOFTEX 2000). Sua estrutura foi implantada em 1997 e no ano 2000 foi criada a ONG "Incubadora Tecnológica de Maringá”. É uma entidade civil sem fins lucrativos e seu principal objetivo é promover a integração entre centros de pesquisas, empresas e comunidade, em nível nacional e internacional, difundir a cultura empreendedora e ser uma alternativa de geração de emprego e de renda (INCUBADORA..., 2010).

A Incubadora Empresarial Santos Dumont faz parte da Fundação Parque Tecnológico Itaipu (PTI). Criada pela Itaipu Binacional no ano de 2003, a fundação tem por finalidade apoiar o desenvolvimento na Região Trinacional de Iguassu, que envolve três países de fronteira: Argentina, Brasil e Paraguai. Os objetivos principais da Incubadora do PTI são os de promover a capacitação dos empreendedores em gestão empresarial e da inovação; estimular o comportamento e atitudes empreendedores; apoiar e promover eventos técnicos, científicos e promocionais que incitem a interação dos empreendimentos com o meio empresarial e científico; articular com organizações públicas e privadas que atuem na promoção do desenvolvimento de empreendimentos inovadores; fomentar o desenvolvimento econômico sustentável, com respeito ao meio ambiente, por meio de apoio a empreendimentos inovadores; e auxiliar na elaboração de propostas que visem obter fomento para projetos inovadores (PTI..., 2011).

O CIT/FUNDETEC é um centro incubador que compõe a FUNDETEC (Fundação para o Desenvolvimento Científico e Tecnológico), uma autarquia pública do município de Cascavel, PR, criada em 1993, que foi ampliada em dezembro de 1996 com a criação do Parque Tecnológico Agroindustrial do Oeste. Além do centro incubador, a fundação ainda possui a AGROTEC, uma escola técnica agropecuária para pesquisa e desenvolvimento de todas as atividades do setor agrícola, oferecendo uma ampla estrutura de capacitação para agricultores, acadêmicos, produtores e proprietários de agroindústrias, ofertando diversos cursos em parceria com outras entidades (FUNDETEC, 2011). A incubadora tem o objetivo de:

estimular a criação e o desenvolvimento de micros e pequenas empresas, subsidiar o surgimento de novos negócios e empresas de produtos, serviços, processos de base tecnológica, com geração de emprego e renda, oferecendo suporte técnico, gerencial e formação complementar ao empreendedor (FUNDETEC, 2011).

Passa-se agora para a descrição do processo de funcionamento das incubadoras, especialmente no que se refere a sua relação com as incubadas, iniciando pelo processo seletivo até a avaliação e graduação dessas empresas.

\section{Atuação das incubaboras}

0 processo de seleção para ingressar nas incubadoras é realizado a partir de um edital permanente de seleção e consiste da apresentação de um projeto, através do plano de negócios com viabilidade técnica, econômica, potencial de crescimento, responsabilidades social e ambiental. Em geral, nas propostas são analisados os parâmetros de inovação, potencial de mercado, a coerência do projeto, a consistência das 
informações, geração de emprego e renda, potencial de impacto na economia local ou regional e responsabilidade ambiental. Posteriormente, o projeto é apresentado para uma comissão julgadora que faz a análise.

Na incubadora de Maringá a banca é formada por três especialistas em projetos: um membro da UEM (Universidade Estadual de Maringá), um membro da ACIM (Associação Comercial e Industrial de Maringá) e um integrante do IDR (Instituto para o Desenvolvimento Regional). Na incubadora do PTI existe um comitê gestor permanente com quatro membros pertencentes ao parque tecnológico, sendo eles: o gerente da incubadora, o coordenador de projetos do parque, um membro representante do ITAI (Instituto de Tecnologia Aplicada e Inovação) e um representante do SEBRAE local. Além desses participantes são convidados mais dois especialistas na temática envolvida, sendo um da academia, geralmente um professor da UNIOESTE (Universidade do Oeste do Paraná) e um representante do mercado. No CIT/ FUNDETEC a análise é feita por membros da incubadora ou até pelo pessoal do conselho curador da FUNDETEC, porém sempre haverá um membro externo, podendo ser um representante do NIT (Núcleo de Inovação Tecnológica da UNIOESTE), que indica um membro dependendo da área em que o projeto pretende atuar.

Após o ingresso, o apoio ofertado pelas incubadoras engloba a infraestrutura física necessária para a instalação e o funcionamento das empresas, como sala de reuniões, showroom, secretaria, sala de treinamento, serviços administrativos e internet, auditório, módulos individuais, biblioteca, suporte técnico e administrativo, serviços de recepção e laboratórios. 0 tempo de permanência como empresa residente é de dois anos, podendo ser prorrogado por mais um ano, sendo considerada graduada ao final do contrato, porém percebe-se que, na prática, as incubadoras apresentam um ambiente flexível no que concerne ao tempo de incubação, pois existem empresas que possuem um tempo maior do que os três anos de incubação, e que, no entanto, ainda não foram graduadas, sendo os contratos renegociados.

Para as empresas incubadas residentes ou não residentes, as incubadoras oferecem apoio na questão de assessoria e consultoria, buscando trazer cursos que capacitem o empreendedor na administração da empresa. Algumas empresas solicitam treinamentos ou a própria incubadora identifica a necessidade de oferecê-los; dependendo da demanda e dos recursos disponíveis, esses treinamentos são oferecidos a custo zero ou baixo custo em relação ao mercado.

Com relação à participação das incubadas em feiras ou eventos, existe a possibilidade de auxílio financeiro. No caso do CIT/FUNDETEC, quando uma empresa precisa participar, "se ela justificar que aquilo é para o desenvolvimento da empresa, se vai ajudar a empresa, então [...] a gente dá esse apoio, tendo recurso, na previsão de recursos, a gente tem esse apoio para participar de feira de eventos" (E6). A incubadora tem buscado informações antecipadas com as incubadas para fazer um planejamento dos eventos e feiras que as empresas pretendem participar, para tentar buscar recursos, através de editais.

Nota-se que as incubadoras agem como intermediárias dos contatos entre as empresas incubadas e os órgãos de fomento para a captação de recursos, permitindo que as incubadas se utilizem desses contatos com pessoas importantes do setor para adquirir novos laços no mercado. Esses recursos são captados em conjunto com as empresas e são exclusivos para financiarem a gestão administrativa e a produção. Pesquisas apontam que a maioria das empresas incubadas se beneficia de seus laços com a incubadora para terem acesso a redes de laços fracos e, consequentemente, conseguirem recursos financeiros para suas empresas, conforme discutido por Elfring e Hulsink (2007).

Em relação à assessoria para a captação de recursos, de acordo com os entrevistados da Incubadora Tecnológica de Maringá, a busca de recursos para as empresas ocorre, normalmente, por meio da incubadora. Para eles existe a facilidade de acesso aos especialistas para desenvolverem os projetos de captação de recursos, por estarem dentro de uma instituição de ensino superior, que é a UEM, e por terem parceria com o CESUMAR (Centro Universitário de Maringá):

a maioria dos recursos que a gente capta por edital [...] é para as empresas, eles podem viajar, participar de feiras, imprimir material para divulgar seus produtos, cartão, todo material de design, de mídia, pra quando eles vão participar de feiras que tem que levar, o próprio prospecto do produto desenvolvido, tudo isso a incubadora, ela capta recursos junto com o empresário (E1).

A incubadora do PTI atua em conjunto com as empresas incubadas na participação de editais 
disponibilizados por agências de fomento, ciente da importância de se adquirir recursos financeiros na fase inicial do empreendimento, principalmente para desenvolver um produto ou uma nova tecnologia. Neste contexto, o gerente da incubadora relata o caso de uma empresa incubada que recebeu o apoio de um consultor para elaboração de um projeto de submissão:

ele recebeu com apoio da incubadora um consultor pra sentar com ele por um período de dois a três meses elaborar um projeto [...] maneiras de colocar isso no papel e falar a linguagem que a agência de fomento pratica, então o consultor já traz esse know-how e acaba sendo muito mais efetivo na elaboração do projeto e aumentando as chances de captar recursos, e o que a gente quer é isso (E4).

No CIT/FUNDETEC nota-se que a prospecção de editais é seu trabalho principal. De acordo com o gestor, "a gente tenta fazer justamente esse meio de campo, a gente sabe das demandas, ou identifica as demandas da região, das empresas e identifica os editais tentando fazer esse meio de campo, tentando fazer esse projeto para juntar" (E6).

Com relação ao acompanhamento das empresas incubadas, cada incubadora adota um processo diferenciado. Na incubadora de Maringá, as empresas têm acompanhamento periódico (a cada seis meses), por meio do GAE (Grupos de Apoio Empresarial), constituído por sete áreas (Tecnologia, Agrárias, Biológicas, Saúde, Sociais, Exatas e Humanas) que são interligadas em redes e que cooperam entre si. Esse grupo aplica um questionário, no qual é avaliado o perfil do empreendimento, informações financeiras, mercado, capacitação e a empresa avalia também a gestão da incubadora. Também são analisados o faturamento, o número de funcionários, se o produto foi inserido no mercado, avaliação do cronograma físico que a empresa estabeleceu para desenvolver o produto, entre outros.

Na incubadora do PTI, os instrumentos de medição para o acompanhamento das empresas estão sendo aprimorados. Hoje ele é realizado trimestralmente, por meio das metodologias do Balanced Scorecard, do Prêmio Nacional da Qualidade, além do planejamento estratégico elaborado pela empresa incubada. Para fazer as análises são realizadas reuniões de acompanhamento coordenadas pelo analista de negócios da Incubadora do PTI e por um consultor do SEBRAE. Durante quatro horas são avaliados, através dos indicadores, os pontos críticos que precisam ser melhorados. Nesta ocasião, são distribuídas tarefas tanto para os sócios das empresas como para a incubadora quando se aplica. No trimestre seguinte, a reunião é realizada com base no que foi construído nos três meses que se passaram.

No CIT/FUNDETEC, o gestor revela que a incubadora ainda não atua profundamente no acompanhamento das empresas. Ele afirma que recebe um relatório semestral das atividades das incubadas, porém um acompanhamento maior ainda está em fase de estruturação, inclusive está se estudando um projeto junto com a ANPROTEC para auxiliar nesse trabalho.

\section{Redes estratégicas e inovação nas} incubaboras paranaenses

Além de oferecer infraestrutura, o papel da incubadora é trabalhar como mediadora de relacionamentos entre as empresas incubadas, o mercado e o acesso a informação, podendo ser vista como uma parceira para a disseminação dos negócios. Por conseguinte, ao mesmo tempo em que as incubadoras apoiam as empresas nas questões referentes à incubação, também as inserem em suas redes sociais. Como consequência, as empresas adquirem novos relacionamentos por meio desse laço com a incubadora, que podem ser utilizados de maneira estratégica pelas incubadas (ELFRING; HULSINK, 2007).

A incubadora de Maringá trabalha em parceria com a UEM, que oferece toda a infraestrutura necessária. Outros parceiros são: CESUMAR, SEBRAE, FIEP, Governo do Estado, TECPAR, ACIM, CODEM (Conselho de Desenvolvimento Econômico de Maringá), IDR, Prefeitura Municipal de Maringá, SINDIMETAL (Sindicato das Indústrias Metalúrgicas, Mecânicas e de Materiais Elétricos do Estado do Paraná), entre outros.

As organizações parceiras da incubadora do PTI são: SEBRAE, UNIOESTE, CERTI (Fundação Centros de Referência em Tecnologias Inovadoras) e o ITAI, este último pertencente ao Parque Tecnológico Itaipu.

As parcerias do centro incubador CIT/FUNDETEC estão associadas às parcerias da fundação; elas possuem projetos juntamente com universidades, como a UNIOESTE, FAG (Faculdade Assis Gurgacz), UNICAMP, UFPR, UTFPR e UNIBAN Brasil; órgãos governamentais, como o Ministério da Agricultura, Ministério de Ciência e Tecnologia, Ministério do Desenvolvimento 
Agrário e o Ministério do Desenvolvimento, Indústria e Comércio Exterior; além de outras entidades como o SEBRAE, CNPq, FINEP, IAPAR, EMATER, entre outros.

As redes das incubadoras buscam propiciar legitimidade às empresas incubadas, dando suporte para que a empresa tenha acesso ao mercado e a informação. Para ganhar reconhecimento, as novas empresas procuram obter um associado de negócios para construir uma forte ligação e esperar que, através desse contato, tenham acesso a novos clientes e parceiros (ELFRING; HULSINK, 2002).

Sobre o acesso ao mercado, nota-se no CIT/ FUNDETEC algumas peculiaridades. Foi relatado pelo gestor que, por estar ligada a um órgão público, a sociedade em geral e até as empresas incubadas ou graduadas, muitas vezes, confundem a incubadora com a própria fundação e até mesmo com a prefeitura, o que pode trazer benefícios dependendo do ramo de atuação da empresa, pois o nome da fundação pode atuar positivamente para setores que conhecem a FUNDETEC e a própria fundação também trabalha de forma conjunta para buscar recursos para a incubadora. Por outro lado, nem todas as empresas têm consciência da importância da rede da fundação para o seu desenvolvimento, ou o nome da fundação não favorece o seu setor de atuação.

Na Incubadora Tecnológica de Maringá, os gestores enfatizam que o fato de estarem dentro da UEM pode trazer o reconhecimento do mercado:

é mais fácil estar dentro de uma instituição de ensino superior do que fora dela. É claro que pra empresa se apresentar, tendo, se ela se apresenta sendo uma empresa incubada, ela carrega todo peso dos nossos parceiros junto com ela. Então isso abre muito mais as portas do que ela se apresentar como uma empresa que acabou de nascer, alguma coisa assim, que não tem o apoio da incubadora por trás (E3).

Para o gerente da incubadora do PTI, as forças da marca de ITAIPU e do próprio PTI propiciam às empresas ali incubadas trânsito positivo para acesso ao mercado, além do respaldo promovido pela parceria com a UNIOESTE, principalmente pelo reconhecimento dos cursos de exatas. Entretanto, ressalta que "sem dúvida é um voto de confiança nesse sentido, da credibilidade para a empresa que está aqui dentro, mas depende da demonstração da implementação de ações concretas por parte dos empresários" (E4).
Quanto ao acesso a informação, a formação de relacionamentos é beneficiada pelas redes das incubadoras, pois as parcerias fomentam as trocas nesse ambiente. Estudo desenvolvido por Elfring e Hulsink (2002) demonstrou nas empresas analisadas que a associação com institutos de pesquisa com uma grande reputação (como as universidades) auxilia na obtenção da legitimidade cognitiva, por exemplo, exploração e aproveitamento dos conhecimentos, as possibilidades de acesso e ampla aceitação da nova empresa. Na Incubadora de Maringá, o fato de se localizar nas instalações da UEM favorece o apoio institucional. Os gestores acreditam que essa rede de contatos favorece o desenvolvimento da inovação na Incubadora, principalmente pelo fato de estarem dentro de uma Instituição de Ensino Superior, que oferece toda estrutura acadêmica e de pesquisa para as empresas formarem parcerias de trabalho com a instituição.

No CIT/FUNDETEC, a grande rede formada pela fundação, prefeitura, incubadora e parceiros parece ser vantajosa, pois quando um deles não pode ser proponente de um projeto, outro parceiro se propõe e todos trabalham de forma conjunta com a rede. O próprio diretor da fundação possui muitos contatos políticos e com outros órgãos devido a sua experiência profissional, o que parece favorecer a rede. "Ele é muito bem relacionado na questão política e trabalhou durante muito tempo no SEBRAE, então ele tem os contatos muito fortes, o pessoal de Brasília, o pessoal de Curitiba" (E6), o que beneficia a troca de informações.

No entanto, como o CIT/FUNDETEC está vinculado à prefeitura, a questão política também influencia no seu trabalho. A política acaba sendo um problema enfrentado pela incubadora, pois com a mudança de governo os funcionários que são servidores da prefeitura, estagiários da prefeitura ou nomeados como cargo de confiança são também substituídos. Percebeu-se na incubadora uma grande rotatividade de pessoal, o que interrompe o trabalho que está sendo realizado e atrapalha no andamento das atividades conjuntas da incubadora e das incubadas, não criando vínculos duradouros de confiança entre as partes. Isso prejudicou as relações entre a incubadora e as incubadas, por esse motivo, neste momento, a incubadora está buscando cuidar da sua própria gestão, para depois dar um apoio maior para as empresas.

A rede formada por parceiros da incubadora do PTI, segundo seu gestor, favorece as empresas incubadas, sobretudo ao promover acesso facilitado aos laboratórios do Parque Tecnológico e troca de 
informações com a academia, principalmente por meio dos cursos da área de exatas da UNIOESTE no campus Foz do Iguaçu. Vale ressaltar que tanto a administração quanto a infraestrutura desses cursos estão sediadas nas instalações do PTI.

Assim, é possível observar que, apesar das incubadoras fomentarem o acesso a informação das empresas, tornando-se uma influência benéfica, como frisado pelos gestores, com relação ao mercado podem existir alguns pontos negativos que devem ser considerados. $\mathrm{O}$ acesso ao mercado pode ser prejudicado, pois o fato de depender de uma instituição pode associar a imagem da empresa à inexperiência, ou inclusive pensar que ela funciona como uma empresa de estudantes, o que pode ocasionar a falta de confiança nos produtos e serviços oferecidos.

Com relação às empresas incubadas, até o ano de 2010, aproximadamente quarenta e cinco empresas, entre pré-incubadas e incubadas, utilizaram a estrutura da Incubadora Tecnológica de Maringá. Atualmente existem oito empresas incubadas internas, sete empresas incubadas externas, treze empresas graduadas e duas empresas graduadas associadas (fase de pós-incubação). No CIT/FUNDETEC, até janeiro de 2011 havia quatorze empresas incubadas e mais quatro aprovadas para incubação, com previsão de efetivação no primeiro semestre de 2011. Além disso, treze empresas já foram graduadas nessa instituição. Quanto à incubadora do PTI, tendo como base março de 2011, estão instaladas nas dependências da Incubadora seis empresas em fase de pré-incubação, dezoito empresas incubadas, sendo cinco não residentes e complementando quatro empresas graduadas.

Sobre os relacionamentos existentes entre as incubadas, nota-se, em geral, que o ambiente percebido é de cooperação. No CIT/FUNDETEC, o gestor revela que:

pelo fato de não serem do mesmo ramo, o que eu percebo é de cooperação, não que seja muita cooperação, mas existe, essa cooperação, às vezes é, são dois ou três aqui, eles sentam e conversam, e o pessoal aqui conhece os outros, são vizinhos de sala vamos dizer, mas essa cooperação às vezes é mais quando é direcionada por nós da FUNDETEC [...] acho que acontece mais facilmente essa cooperação (E6).

Na Incubadora Tecnológica de Maringá, entre as incubadas houve casos de formarem parcerias e também de fusão de duas empresas. "Então acontece de tudo. É muito bacana e o ambiente aqui é propício pra isso, e nós procuramos fazer com que elas sempre se conversem, uma sabe do que a outra está fazendo pra ocorrer este tipo de troca" (E3).

0 gestor da incubadora do PTI entende que incentivar a cooperação entre as empresas incubadas é uma das atribuições da Incubadora, neste sentido existe um movimento coordenado de fortalecimento de culturas e boas práticas direcionadas para esta finalidade. Nas palavras do gestor:

a gente vem trabalhando muito, estimulando muito, essa interação entre os empresários, não só internamente, como externamente também com outras incubadoras, empresas incubadas em outras incubadoras [...] até internacionalmente a gente tem uma rede Brasil, Paraguai, Argentina de incubadoras, nós tivemos o mês passado uma videoconferência, onde tinha empresas incubadas nos três países (E4).

Conforme observado, é possível afirmar que, por estarem dentro da incubadora, as empresas possuem acesso a laços que se desenvolvem ao longo do tempo e esses laços podem se tornar importantes para o desenvolvimento das empresas em algum momento, pois existe a troca de informações entre elas e a formação de algumas parcerias dentro das incubadoras. A condição de cooperação e parceria ocorre nas três incubadoras, e pode-se ressaltar que os gestores estão cientes dessa necessidade e procuram impulsionar a interação entre as incubadas.

Estudos comprovam que os membros de múltiplos grupos coesos possuem mais acesso a diversos recursos, facilitando seu processo de inovação e criação de novos produtos (VEDRES; STARK, 2010). Neste sentido, em relação à rede de parceiros das incubadoras estudadas, observa-se que há uma diversidade de contatos, o que pode contribuir para a troca de informações. A condição de troca em rede pretende beneficiar o ambiente das incubadoras, pois os contatos com universidades e centros de pesquisas podem favorecer a geração de ideias. A inovação é um pré-requisito ímpar para a incubação de uma empresa, apesar disto, na prática, pode-se inferir que essa realidade é discutível.

A definição de inovação para o CIT/FUNDETEC pode ser encontrada nos documentos analisados. No edital permanente de incubação, exige-se que a empresa apresente proposta baseada em inovação tecnológica de acordo com o artigo 17, parágrafo $1^{\text {ㅇ }}$ 
da Medida Provisória n. 252 de 15/06/2005, o qual considera como "inovação tecnológica a concepção de novo produto ou processo de fabricação, bem como a agregação de nova funcionalidade ou característica ao produto ou processo que implique em melhoria e efetivo ganho de qualidade e produtividade, resultando em maior competitividade". Entretanto, o conceito de inovação parece estar vinculado ao contexto da região, pois, como declara o gestor, "às vezes, eu vejo que a gente tenta abrir um pouco mais, às vezes não se entende como inovação fora do contexto da nossa região, mas na nossa região acaba sendo uma inovação" (E6).

Na Incubadora de Maringá, os gestores entendem a inovação como a criação de algo novo que tenha "um componente diferente do que já existe, né. Que possa atender uma demanda que ainda não foi totalmente atendida, um nicho do mercado talvez não atendido" (E2). Para outro entrevistado, a inovação:

corresponde à produção no mercado de um produto, bem ou serviço, novo ou significativamente melhorado, ou a introdução por parte da empresa de processos novos, né, ou melhorados no processo de desenvolvimento dela. [...] E o que vai depois dizer se isto é realmente uma inovação ou não vai ser a aceitação ou não pelo mercado deste produto que a empresa está desenvolvendo (E3).

Na Incubadora do PTI, a princípio, quando a empresa se candidata a ingressar na incubadora, ela deve apresentar algum grau de inovação no produto, serviço ou em processos que se propõe realizar. Neste sentido, o conceito de inovação utilizado na seleção de uma empresa é o impacto que a nova ideia pode trazer para o mercado, principalmente para o mercado regional. Segundo o gestor, a empresa deve "apresentar um certo nível de inovação no mínimo local ou regional, então na seleção a gente avalia se inovação incremental ou se chega a ser radical, considerando os níveis local, regional, nacional e global" (E4).

Percebe-se que o conceito de inovação nas três incubadoras é semelhante, pois ela é considerada em nível local e regional, estando vinculado ao contexto da região. Por esse motivo, analisa-se que o tipo de inovação comumente adotado pelas empresas incubadas é do tipo incremental, que procura melhorar algo já existente (MOREIRA; QUEIROZ, 2007). A inovação do tipo radical, que muda completamente um processo (TIDD; BESSANT; PAVITT, 2008), é mais difícil de ocorrer.

Para o gestor da Incubadora do PTI (E4), a inovação radical tem maior probabilidade de ocorrer nos grandes centros de pesquisa aplicada e aponta forte interesse em estreitar as parcerias no que tange às pesquisas realizadas nas instituições de ensino superior estabelecidas na região. De acordo com suas impressões:

a gente vê muito potencial ainda para se aumentar, então a gente tem um campus da UNIOESTE aqui dentro [...] nosso trabalho tem sido levar até os alunos de graduação e os eventuais grupos de pesquisas existentes, a oportunidade de empreender uma ideia que por ventura os alunos e pesquisadores vejam que pelo menos tenham uma leve impressão de que tenha possibilidade de se tornar um negócio, [...] outras faculdades de outras cidades daqui da região oeste (E4).

Nas incubadoras existem diversos tipos de empresas voltadas a inúmeras áreas, tais como: desenvolvimento de software, ramo alimentício, gestão e educação ambiental, consultorias, agronegócio, meio ambiente - que é forte na região paranaense, empresas cooperativas e associações, entre outras. Na Incubadora de Maringá e no CIT/FUNDETEC, nota-se que não há uma predominância de empresas do mesmo ramo. Essa diversificação colabora para que não haja concorrência no ambiente, contudo não fomenta a troca de experiências no ramo entre as incubadas. Desta forma, analisa-se que o acesso a informação influencia a inovação das empresas incubadas, pois existem trocas constantes, porém esse acesso ainda é irrisório se comparado às necessidades das empresas.

Um ponto importante a ser discutido nesse sentido é a diferença do significado de tempo para as empresas incubadas, para a incubadora e para as universidades, pois uma pesquisa universitária necessita de um tempo maior para seu desenvolvimento e o mercado segue com mudanças rápidas. No caso do CIT/FUNDETEC e da Incubadora do PTI, por fazerem parte de um órgão público, o significado de tempo também influencia na atuação das incubadoras e, por consequência, nas incubadas, pois todas as saídas de capital precisam passar por processos licitatórios, o que pode ocasionar morosidade, fato que não condiz com a natureza dinâmica de empresas inovadoras, 
tendo em vista a rapidez do fluxo de informações e do mercado.

Diante do exposto, nota-se que as incubadoras, na percepção de seus gestores, tentam fomentar o ambiente de inovação, tanto com parcerias entre as incubadas quanto de parcerias entre as incubadas e os centros de pesquisa, dando ênfase na tentativa de procurar recursos para o desenvolvimento das empresas. Sendo assim, verifica-se que a incubadora atua como intermediária de relacionamentos, porém os gestores sabem que ainda precisam melhorar em muitos aspectos, principalmente em relação ao apoio de acesso ao mercado e de acompanhamento do desempenho das incubadas.

\section{Considerações finais}

Dentro do objetivo da pesquisa de analisar, em redes estratégicas, se a incubadora, a partir da perspectiva dos seus gestores, atua como intermediária das empresas incubadas no acesso a informação para o desenvolvimento de inovação, podem ser destacados quatro achados.

Primeiro, as incubadoras têm consciência da necessidade de realização do papel de intermediária para a formação de redes estratégicas, e, pelo menos no discurso, buscam atingi-lo. Os gestores das incubadoras argumentam que incentivam a interação entre as incubadas e das incubadas com outras organizações, além disso, mantêm um grupo de parceiros com os quais as incubadas podem contar. Todavia, nenhum mecanismo formalizado e institucionalizado foi destacado pelos entrevistados.

0 segundo achado refere-se à dificuldade de formação de relacionamentos dentro da incubadora devido à existência de uma diversidade nos tipos de empresas que são incubadas. Em virtude das três incubadoras aceitarem incubar empresas de diversas áreas, cria-se uma dificuldade de trabalho conjunto. Apesar de autores como Vedres e Stark (2010) destacarem que são justamente as diferenças, em virtude da diversidade de informações, que podem levar à inovação, se não existir algo em comum entre as empresas ou algum mecanismo formalizado que facilite a comunicação, diminui o estímulo para que elas formem parcerias.

É importante frisar que a falta de interesse por parte do empreendedor para a formação de relacionamentos também aparece como um agente desestimulante, pois por mais que existam incentivos, sem o interesse e a disponibilidade de tempo para a interação e a troca de informações, nada pode ser feito.

0 terceiro achado está relacionado à diferença que existe da noção de tempo entre as incubadas, as incubadoras, instituições de pesquisa e universidades. Para as incubadas as coisas precisam acontecer rápido devido às pressões do mercado, já nas incubadoras e universidades as coisas demoram mais para acontecer, seja por causa dos procedimentos burocráticos ou por causa do tempo de realização de uma pesquisa.

0 quarto achado a ser destacado é que nas três incubadoras as inovações possuem um baixo grau de novidade, sendo que aparecem com mais frequência inovações incrementais voltadas ao âmbito local e regional. Esse fato pode ser explicado de três formas: a primeira das explicações é a característica agropecuária da região pesquisada, o que facilita o acesso a recursos e informações voltados para esse mercado. A segunda possibilidade de explicação está relacionada à própria característica das incubadoras, que apesar de possuírem em seus nomes o título de tecnológicas, abrem-se para todos os tipos de empreendimentos. Por último, pode-se ainda discutir o fato de as pesquisas de ponta não encontrarem espaço em regiões interioranas. Um estado como o Paraná, com características fortemente agrícolas, em certa medida periférico em termos de pesquisa tecnológica, e ainda as regiões mais afastadas da capital, tem dificuldade de criar espaços de desenvolvimento tecnológicos mais avançados.

Finalmente, este estudo propõe que trabalhos futuros podem ser realizados com o intuito de pesquisar a visão dos empreendedores sobre o papel da incubadora, visando confrontar o discurso de ambas as partes.

\section{Referências}

ALBAGLI, S.; MACIEL, M. L. Informação e conhecimento na inovação e no desenvolvimento local. Ciência da Informação, v. 33, n. 3, p. 9-16, 2004.

ANDRADE, T. N. Inovação e ciências sociais: em busca de novos referenciais. Revista Brasileira de Ciências Sociais, v. 20, n. 58, p. 145-211, 2005. 
ARBIX, G. Inovação e desenvolvimento. In: ARBIX, G. et al. (Org.). Inovação: estratégia de sete países. Brasília: ABDI, 2010.

ASSOCIAÇÃO NACIONAL DE ENTIDADES PROMOTORAS DE EMPREENDIMENTOS INOVADORES - ANPROTEC. SERVIÇO BRASILEIRO DE APOIO ÀS MICRO E PEQUENAS EMPRESAS - SEBRAE. Glossário dinâmico de termos na área de tecnópoles, parques tecnológicos e incubadoras de empresas. Brasília, 2002.

ASSOCIAÇÃO NACIONAL DE ENTIDADES PROMOTORAS DE EMPREENDIMENTOS INOVADORES - ANPROTEC. Disponível em: <http://www.anprotec.org.br>. Acesso em: 8 abr. 2011.

BARDIN, L. Análise de conteúdo. Lisboa: Edições 70, 1977.

BANDEIRA-DE-MELLO, R. Softwares em pesquisa qualitativa. In: GODOI, C. K.; BANDEIRA-DE-MELLO, R.; SILVA, A. B. (Org.). Pesquisa qualitativa em estudos organizacionais: paradigmas, estratégias e métodos. São Paulo: Saraiva, 2006.

BAUER, M. W. Análise de conteúdo clássica: uma revisão. In: BAUER, M. W.; GASKELL, G. Pesquisa qualitativa com texto, imagem e som: um manual prático. Petrópolis: Vozes, 2007.

BEUREN, I. M.; RAUPP, F. M. Gestão do conhecimento em incubadoras brasileiras. Future Studies Research Journal, v. 2, n. 2, p. 186-210, 2010.

BESSANT, J.; TIDD, J. Inovação e empreendedorismo. Porto Alegre: Bookman, 2009.

CASTILLA, E. J. et al. Social networks in silicon valley. In: LEE, C. M. et al. (Ed.). The silicon valley edge: a habitat for innovation and entrepreneurship. Stanford: Stanford University Press, 2000. p. 218-247.

CASTRO, S. C.; MACHADO, H. V. Empresas de base tecnológica egressas de incubadoras paranaenses: fatores de mortalidade. In: MACHADO, H. V. (Org.). Causas de mortalidade de pequenas empresas. Maringá: EDUEM, 2007.

CONE, J. D.; FOSTER, S. L. Dissertations e theses from start to finish. 2nd ed. Washington: American Psychological Association, 2006.

CRESWELL, J. W. Projeto de pesquisa: métodos qualitativo, quantitativo e misto. 2. ed. Porto Alegre: Artmed, 2007.

DAMANPOUR, F.; SCHNEIDER, M. Phases of the adoption of innovation in organizations: effects of environment, organization and top managers. British Journal of Management, v. 17, n. 3, p. 215-236, 2006.

DENZIN, N. K.; LINCOLN, Y. S. Handbook of qualitative research. Thousand Oaks: Sage, 1994.
DIAS, R. M. Redes estratégicas: a influência do capital social na formação do capital intelectual das empresas focais. 2009. 232 f. Tese (Doutorado em Administração) Fundação Getúlio Vargas, São Paulo, 2009.

ELFRING, T.; HULSINK, W. Networks effects on entrepreneurial processes: start-ups in the Dutch ICT Industry 1990-2000. In: CONFERENCE UNIVERSITAT AUTONOMA DE BARCELONA, 16., 2002, Barcelona. Proceedings... Barcelona: RENT, 2002.

ELFRING, T.; HULSINK, W. Networking by entrepreneurs: patterns of tie-formation in emerging organizations. Organization Studies, v. 28, n. 12, p. 1849-1872, 2007.

FONTANA, A.; FREY, J. H. Interviewing: the art of science. In: DENZIN, N. K.; LINCOLN, Y. S. (Org.). Handbookof qualitative research. Thousand Oaks: Sage, 1994. p. 361-376.

FUNDAÇÃO PARA O DESENVOLVIMENTO CIENTÍFICO E TECNOLÓGICO - FUNDETEC. Disponível em: <http:// www.fundetec.org.br>. Acesso em: 27 fev. 2011.

GODOY, A. S. Estudo de caso qualitativo. In: GODOI, C. K.; BANDEIRA-DE-MELLO, R.; SILVA, A. B. (Org.). Pesquisa qualitativa em estudos organizacionais: paradigmas, estratégias e métodos. São Paulo: Saraiva, 2006. p. 1-13.

GRANOVETTER, M. The strength of weak ties. American Journal of Sociology, v. 78, n. 6, p. 1360-1380, 1973.

GRANOVETTER, M. Economic action and social structure: the problem of embeddedness. American Journal of Sociology, v. 91, n. 3, p. 481-510, 1985.

GULATI, R.; NOHRIA, N.; ZAHEER, A. Strategic networks. Strategic Management Journal, v. 21, n. 3, p. 203-215, 2000.

INCUBADORA TECNOLÓGICA DE MARINGÁ. Disponível em: <http://www.incubadoramaringa.org.br/novo/index. php>. Acesso em: 5 out. 2010.

LAHORGUE, M. A. Pólos, parques e incubadoras: instrumento de desenvolvimento do século XXI. Brasília: Evangraf, 2004.

LEMOS, C. Inovação na era do conhecimento. In: LASTRES, H. M. M. Informação e globalização na era do conhecimento. Rio de Janeiro: Campus, 1999.

MACHADO, H. V.; GREATTI, L.; JESUS, M. J. Compreendendo a imersão de empreendedoras em redes: a institucionalização da associação de mulheres de negócios de Maringá. In: GIMENEZ, F. A. P.; FERREIRA, J. M.; RAMOS, S. C. (Org.). Empreendedorismo e estratégia de empresas de pequeno porte - 3Es2Ps. Curitiba: Champagnat, 2010. p. 85-104. 
MACIEL, M. L. Hélices, sistemas, ambientes e modelos: os desafios à sociologia da inovação. Sociologias, v. 3, n. 6, p. 18-29, 2001.

MINISTÉRIO DA CIÊNCIA E TECNOLOGIA. Disponível em: <http:// www.mct.gov.br>. Acesso em: 17 out. 2009.

MOREIRA, D. A.; QUEIROZ, A. C. S. (Org.). Inovação organizacional e tecnológica. São Paulo: Thomson Learning, 2007.

MOWERY, D.; ROSENBERG, N. Trajetórias da inovação: a mudança tecnológica nos Estados Unidos da América no Século XX. Campinas: Unicamp, 2005.

NONAKA, I. A empresa criadora do conhecimento. In: STARKEY, K. (Org.). Como as organizações aprendem: relato do sucesso das grandes empresas. São Paulo: Futura, 1997. p. 27-43

PARQUE TECNOLÓGICO ITAIPU - PTI. Disponível em: <http://www.pti.org.br>. Acesso em: 1ํo mar. 2011.

POWELL, W.; SMITH-DOERR, L. Network and economic life. In: SMELSER, N. J.; SWEDBERG, R. (Org.). The handbook of economic sociology. Princeton, N. J.: Princeton University Press, 1994. p. 268-403.

PRAJOGO, D.; AHMED, P. Relationship between innovation stimulus, innovation capacity and innovation performance. R\&D Management, v. 36, n. 5, p. 499-515, 2006.

REDE PARANAENSE DE INCUBADORAS E PARQUES TECNOLÓGICOS. Disponível em: <http://www. reparte.org. br>. Acesso em: 8 abr. 2011.

RICHARDSON, R. J. Pesquisa social: métodos e técnicas. 3. ed. São Paulo: Atlas, 2008.

ROGERS, E. Diffusion of innovation. New York: Free Press, 2003.
TÁLAMO, M. F. G. M. A pesquisa: recepção da informação e produção do conhecimento. DataGramaZero - Revista de Ciência da Informação, v. 5, n. 2, art. 1, 2004.

TIDD, J.; BESSANT, J.; PAVITT, K. Gestão da inovação. Porto Alegre: Bookman, 2008.

TOMAÉL, M. I. et al. Das redes sociais à inovação. Ciência da Informação, v. 34, n. 2, p. 93-104, 2005.

TRIVIÑOS, A. Introdução à pesquisa em ciências sociais: a pesquisa qualitativa em educação. São Paulo: Atlas, 2008. UZZI, B. Social structure and competition in interfirm networks: the paradox of embeddedness. Administrative Science Quarterly, v. 42, n. 1, p. 35-67, 1997.

VEDOVELLO, C.; FIGUEIREDO, P. Incubadora de inovação: que nova espécie é essa? RAE Eletrônica, v. 4, n. 1, p. 1-18, 2005.

VEDRES, B.; STARK, D. Dobras estruturais: ruptura generativa em grupos sobrepostos. Revista de Administração de Empresas, v. 50, n. 2, p. 215-240, 2010.

YIN, R. K. Estudo de caso: planejamento e métodos. 2. ed. Porto Alegre: Bookman, 2003.

Recebido: 19/09/2011

Received: 09/19/2011

Aprovado: 11/10/2011

Approved: 10/11/2011 